\title{
Validation and preliminary results of the Parental Assessment of Children's External genitalia scale for Females (PACE-F) for girls with CAH
}

Konrad M. Szymanski, ${ }^{a}$ MD MPH, Benjamin Whittam, ${ }^{a}$ MD MS, Patrick O. Monahan, ${ }^{b}$ PhD, Martin Kaefer, ${ }^{\mathrm{a}}$ MD, Heather Frady, ${ }^{\mathrm{a}} \mathrm{RN}$ BSN, Mark P. Cain, ${ }^{\mathrm{a}}$ MD, Richard C. Rink, ${ }^{\mathrm{a}}$ MD ${ }^{a}$ Division of Pediatric Urology, Riley Hospital for Children at Indiana University Health, Indianapolis, Indiana, United Sates

${ }^{b}$ Department of Biostatistics, Indiana University School of Medicine and School of Public Health, Indianapolis, Indiana, United Sates

\section{Corresponding author:}

Konrad M. Szymanski, MD MPH

Division of Pediatric Urology

Riley Hospital for Children at IU Health

705 Riley Hospital Dr., Suite 4230

Indianapolis, IN 46202, USA

Tel: (317) 944-7446

Fax: (317) 944-7481

Email: szymanko@iupui.edu

Short title suggestion: Parental Assessment of Children's External genitalia scale for girls with $\mathrm{CAH}$

\section{Declaration of interest: none}

This is the author's manuscript of the article published in final edited form as:

Szymanski, K. M., Whittam, B., Monahan, P. O., Kaefer, M., Frady, H., Cain, M. P., \& Rink, R. C. (2019). Validation and Preliminary Results of the Parental Assessment of Children's External Genitalia Scale for Females (PACE-F) for Girls With Congenital Adrenal Hyperplasia. Urology. https://doi.org/10.1016/j.urology.2019.04.034 
Word count: Abstract (249), Manuscript (3000)

Keywords: adrenal hyperplasia, congenital; parent reported outcome measures; urogenital surgical procedures

Funding: Departmental research fund

Internal review board approval: 1512039731

Objective: To validate a Parental Assessment of Children's External genitalia scale for Females (PACE-F) for girls with Congenital Adrenal Hyperplasia $(\mathrm{CAH})$ by adapting the validated adult Female Genital Self-Image Scale.

Methods: PACE-F was administered to parents of girls (Tanner 1, 2 months-12 years) with and without CAH. Final questions were determined by clinical relevance and psychometric properties (scores: 0-100). A reference range was established using 95\% confidence interval among controls. Age-matched controls were compared to girls with $\mathrm{CAH}$ a) $<4$ years old before and after Female Genital Reconstruction Surgery (FGRS), and b) 4-12 year olds after FGRS. Non-parametric statistics were used.

Results: Participants included 56 parents of 41 girls with CAH (median 3.9 years old, $97.6 \%$ FGRS) and 139 parents of 130 girls without CAH. Face and content validity was established by families, experts and factor analysis. Internal consistency was high (Cronbach's alpha: 0.83). Population reference score range was 66.7-100. Ten consecutive girls had pre- and post-FGRS 
PACE-F scores. All scores improved at 4 months after surgery and all preoperative scores were below reference range and lower than controls $(\mathrm{p}=0.0001)$. All post-operative scores were within reference range, no different from controls $(p=0.18)$. Scores for girls with CAH after FGRS aged 4-12 years were no different from controls (100.0 vs. 88.9, $\mathrm{p}=0.77)$ and $90.0 \%$ were in reference range, as expected $(\mathrm{p}=0.99)$.

Conclusions: We present a validated instrument for parental assessment of genital appearance in girls with CAH. We demonstrate improved parent-reported appearance after FGRS, with scores similar to age-matched controls.

Abbreviations: CAH: Congenital Adrenal Hyperplasia, FGRS: Female Genital Restoration Surgery, PRO: Patient-/Parent-Reported Outcome, FGSIS: Female Genital Self-Image Scale, PACE-F: Parental Assessment of Children's External genitalia scale for Females, SD: Standard Deviation, MID: Minimal clinically Important Difference, SEM: Standard Error of Measurement, SRM: Standardized Response Mean, PUM: Partial Urogenital sinus Mobilization

\section{Introduction}

Congenital adrenal hyperplasia $(\mathrm{CAH})$ is the most common etiology of ambiguous genitalia in newborns. ${ }^{Y-3}$ The appropriateness and timing of female genital restoration surgery (FGRS) in females with $\mathrm{CAH}$ is an area of debate. ${ }^{4,5}$ Adding to ethical considerations are concerns that outcomes may differ for surgeries performed in infancy versus puberty. ${ }^{6,7}$ Limited data supports either approach. ${ }^{8,9}$ Since physician interpretations of patient and parental views are prone to 
bias, under-reporting and minimization, ${ }^{10,11}$ validated methods of obtaining patient/parentreported outcomes (PROs) are necessary.

While patient's perceptions are essential, parents currently make the early management decisions. Improved parental perception after FGRS has never been reliably documented in the literature. Moreover, without a validated tool for such an assessment in girls with and without genital ambiguity, reliable studies of relationships between anatomy, parental perceptions and, most importantly, perceptions by females themselves cannot be performed. The 4-item Female Genital Self-Image Scale (FGSIS) was validated in a large national sample of adult women without known genital ambiguity, measuring women's perceptions about their genital appearance. ${ }^{12}$ Lack of an age-appropriate parental FGSIS version precludes its use in children with genital ambiguity. We aimed 1) to validate a Parental Assessment of Children's External genitalia scale for Females (PACE-F) for girls with CAH by adapting the FGSIS, and 2) to report preliminary results of the PACE-F in girls with CAH. We hypothesized that PACE-F scores are lower for girls with CAH without FGRS than girls after FGRS and girls without CAH.

\section{Methods}

We performed an IRB-approved study of parents of girls (Tanner 1, 2 months-12 years old) with $\mathrm{CAH}$ at pediatric urology clinics and without $\mathrm{CAH}$ (controls) at pediatrician clinics and among hospital staff and colleagues (2016-2018). Girls with CAH were followed at our institution before and after FGRS, all performed by age three largely by a single surgeon (2005-2018). Parents of 105 children with $\mathrm{CAH}$ with contact information were eligible. Exclusion criteria for 
control participants were: girls having diagnoses suggestive of abnormal genitalia/perineum or conditions predisposing to frequent genital examinations (genital concerns, history of urinary tract infections, hematuria, clean intermittent catheterizations, neurogenic bladder, imperforate anus). Controls presenting for routine checkup appointments received a $\$ 5$ gift card.

\section{Instrument Development}

We used a step-wise approach to develop a brief, clinically useful instrument capturing parental perceptions of genital appearance of girls with CAH. First, the 4-item FGSIS was reworded to be age-appropriate and reflect parental, rather than patient, responses. It was revised after piloting with 4 parents and 6 clinicians. Responses were made on a 4-point Likert scale (strongly disagree, disagree, agree, strongly agree), like the original FGSIS instrument. Readability was assessed by the Flesch-Kincaid Grade Level test. ${ }^{13}$

\section{Item reduction}

Item reduction is commonly performed to arrive at shorter instruments without compromising utility. Each of the 4 reworded items was examined for medical plausibility, clinical relevance and parental comfort ("I am comfortable answering this question:" strongly disagree, disagree, agree, strongly agree; not validated). We performed a principal axes method of factor analysis and inspection of the scree plot inflexion point. ${ }^{14,15}$ Since at least 3 items with loadings $>0.4$ would be required for a functional instrument, ${ }^{14,15}$ one item could and was dropped. Factor analysis was used to assess whether the original 4 items, or a reduced set of 3 , reasonably satisfied unidimensionality. Factor analysis of 4 items would require 20 participants (at least 5 participants/item) for adequate statistical estimation. ${ }^{16,17}$ 


\section{Validation}

Since PACE-F is a parent-reported measure, it was more appropriate to treat each parental response, rather than an individual child, as the unit of analysis during the validation. We assessed several types of validity to determine if PACE-F measures what it was intended to measure. ${ }^{18}$ Face and content validity were established through a review by parents and experts. Construct validity was assessed through 1) factor analysis in the CAH group and 2) comparing PACE-F scores between children with and without CAH, regardless of history of FGRS. We calculated the domain means, standard deviations (SD), medians, ranges and percentages of subjects scoring the minimum (floor) and maximum (ceiling).

Reliability (reproducibility) was assessed by measuring internal consistency with Cronbach's alpha (0.7-0.9 signifies robust consistency without redundancy). Cronbach's alpha for the 4-item FGSIS is $0.86 .^{12}$

Convergent validity evaluates the degree to which PACE-F scores converge with other instruments measuring similar outcomes or a gold standard. No instrument similar to PACE-F exists, thus we compared PACE-F scores between parents expressing different levels of comfort with changing diapers in a public bathroom for children $<4$ years old ("I am comfortable changing my child's diapers in a public bathroom or change room:" strongly disagree, disagree, agree, strongly agree; not validated) and, when available, surgeon-assessed pre-FGRS level of virilization (Prader scale). 


\section{Clinical utility}

To determine a reference range of PACE-F values for future clinical use, we used the one-sided (lower) 95\% confidence interval of scores from parents for girls without $\mathrm{CAH}$, a method previously used by the World Health Organization. ${ }^{19}$ Two distribution-based approaches were used to determine the minimal clinically important difference (MID) in PACE-F scores that could be appreciated by individuals. Differences were determined using $0.5 \mathrm{SD}^{20}$ and 1.0 standard error of measurement (SEM), where SEM was defined as SD* 1 (1-Cronbach's alpha). ${ }^{21,22}$ We selected the most conservative, largest point difference calculated by these methods as the MID.

\section{Differences between parents}

Maternal and paternal PACE-F scores were compared to determine if parents provided similar scores for their daughter.

\section{Age-matched comparisons}

Since clinically meaningful analyses apply to individual patients, each child was the unit of analysis for each of the 3 comparisons between girls with $\mathrm{CAH}$ and age-matched controls. Because maternal and paternal PACE-F scores did not differ significantly (see Results), a mean of the two scores was used when both were provided. Findings were similar when each analysis was repeated with parental scores as the unit of analysis (not shown).

1) The first comparison included only girls with prospectively collected pre- and post-FGRS PACE-F scores. In order to capture all post-FGRS PACE-F scores for patients whose surgery 
occurred by the age of three, this analysis was restricted to girls younger than 4. An association between post-FGRS changes in PACE-F scores and changes in levels of comfort changing diapers in a public bathroom was tested to assess sensitivity, or responsiveness, of PACE-F, another form of validity.

2) The second analysis consisted of single-time point scores for girls $<4$ years old with only a pre- or post FGRS assessment.

3) The third comparison included single time-point PACE-F scores of 4-12 year olds with CAH (all after FGRS) and controls.

\section{Sensitivity to change validity}

To quantify effect size observed in the prospective analysis, we calculated a standardized response mean (SRM) by dividing the mean change in scores by the SD of the change in scores. $^{23,24}$ Effect size can be categorized as small (0.2-0.5), moderate (0.5-0.8) and large (>0.8). SRM can be helpful in future power calculations.

\section{Statistics}

Study data were managed using REDCap. ${ }^{25}$ Due to skewed score distributions, non-parametric statistics were used (Fisher's exact test for categorical variables; Wilcoxon rank sum and Kruskạt-Wallis rank tests for cross-sectional comparisons of continuous data; Wilcoxon matched-pairs signed-rank test to compare scores before/after surgery). Factor analysis was used, as described above. Linear regression was used to test if PACE-F scores varied with age 
among controls. A critical p=0.05 was used (software: Stata, StataCorp, College Station, TX, USA).

\section{Results}

Overall, 56 parental questionnaires were completed for 41 girls with CAH (38.7\% response rate). Nineteen questionnaires were for 14 girls < 4 years old without FGRS and 37 were after FGRS (17 for girls $<4$ years old, 20 for girls $4-12$ year). Ten girls $<4$ years old had pre- and post-FGRS scores collected prospectively (23 parental responses, Analysis 1). Eleven girls <4 years old (13 parental responses) had either a pre-FGRS (4) or post-FGRS scores (7) (Analysis 2). Twenty girls 4-12 years had post-FGRS scores from 20 parents (Analysis 3). Fourteen of the last 15 $(93.3 \%)$ consecutive families assed at our institution participated.

Median age of 41 girls with CAH was 3.9 years old at end of the study (95.1\% salt-wasting 21hydroxylade deficiency). Forty girls underwent FGRS at median age of 8 months (range: 2 to 37 months; 1 did not have surgery) with a median follow-up 2.9 years. Only one girl underwent surgery at another center. Overall, $87.5 \%$ of girls underwent vaginoplasty $(71.4 \%$ posterior skin flap, $20.0 \%$ posterior sinus flap, $8.6 \%$ pull-through), $92.5 \%$ partial urogenital sinus mobilization $(\mathrm{PUM})^{26}$ and $95.0 \%$ clitoroplasty. Preoperative Prader scale was documented for 21 girls:

Prader 3 in $47.6 \%, 4$ in $47.6 \%$ and 5 in $4.8 \%$. 
Regarding controls, 139 parents of 130 girls without $\mathrm{CAH}$ participated. Parents in the $\mathrm{CAH}$ group were undistinguishable from parent controls in terms of age ( 36 vs. 36 years, $p=0.59$ ) and proportion being fathers $(16.1 \%$ vs. $23.9 \%, \mathrm{p}=0.26)$.

\section{Construct validity}

Like the original 4-item FGSIS, all PACE-F items loaded significantly on one factor, accounting for $87.4 \%$ of item variance. Factor loadings were high for item 1 (satisfaction: 0.94), item 2 (comfort: 0.97) and item 4 (embarrassment: 0.49). Item 3 ("I think my child's genitals smell fine"), was not retained because it had a loading <0.4 (0.11), was least clinically relevant and least comfortable for parents to answer. The scree plot indicated a single dominant dimension, especially after deleting Item 3.

The final 3-item PACE-F has grade 7 readability, takes 1 minute to complete and is scored 0100, where higher values signify higher satisfaction (Table 1). Median PACE-F score for the whole CAH groups was 66.7 (range 11.1-100.0), mean: 67.3 (SD 28.1) (Table 2). A ceiling effect was observed, with $28.6 \%$ of responses being the maximal possible score of 100 . Importantly, all scores for girls without FGRS were less than 100, indicating the ceiling effect applies only after FGRS (and to controls). Without considering FGRS history, median scores were lower in CAH group than controls $(\mathrm{p}=0.0001)$.

\section{Internal reliability}

The initial 4-item PACE-F had a Cronbach's alpha of 0.73 among parents of girls with CAH. After excluding the "smell item," the Cronbach's alpha for the 3-item PACE-F was 0.83, 
suggesting improved internal consistency without redundancy. Not surprisingly, the 3-item PACE-F Cronbach's alpha for controls was 0.90, indicating that PACE-F items are redundant among parents of healthy girls.

\section{Convergent validity}

Stronger parental comfort changing diapers in a public bathroom was associated with higher PACE-F scores of girls with $\mathrm{CAH}<4$ years old ( $\mathrm{p}=0.03$, Figure 1). Among 13 girls with a documented pre-FGRS Prader grade and PACE-F scores, greater virilization was associated with slightly lower PACE-F scores, although this did not reach statistical significance. This was true for individual parental scores (8 parents Prader 3: 44.4 vs. 11 Prader 4-5: 33.3, p=0.40) and average scores per child if both parents participated (6 children Prader 3: 38.5 vs. 7 Prader 4-5: 33.3, $\mathrm{p}=0.36)$.

\section{Population reference range of PACE-F scores}

Median score for controls was 100, although $46.8 \%$ of parents reported lower scores (Table 2). The $95 \%$ confidence interval of scores was $66.7-100.0$, meaning that scores below 66.7 would be considered outside of the population range. PACE-F scores did not vary by child's age in the first 12 years of life on linear regression $(\mathrm{p}=0.15)$ or between children younger than 4 and 4-12 years old $(\mathrm{p}=0.11)$.

\section{Minimally important difference}

The minimally important difference in PACE-F scores that can be appreciated clinically was 14.1 (14.1 for 0.5 SD, 11.6 for SEM using Cronbach's alpha). Since there are 10 possible scores 
for the 3-item PACE-F, each being 11.1 points apart, a difference of at least 22.2, but not 11.1 would be perceivable to an individual.

\section{PACE-F scores reported by mothers and fathers}

Only 5 mother-father pairs provided individual pre-FGRS PACE-F scores, limiting comparison of the two parents. Pairing these scores, mothers and fathers reported undistinguishable scores (median: 33.3 vs. $33.3, \mathrm{p}=0.99$ ).

\section{Prospective analysis: Girls <4 years old with CAH undergoing FGRS}

Baseline and post-operative PACE-F scores were available for 10 girls undergoing FGRS (23 parental responses). FGRS occurred at median 8 months old (80.0\% vaginoplasty, $100.0 \%$ PUM, 100.0\% clitoroplasty). All scores improved at median 4 months after surgery (median: 38.9 vs. $88.9, \mathrm{p}=0.01$, Figure 2). Pre-FGRS scores were lower than age-matched controls $(\mathrm{p}=0.0001)$ and post-operative scores were undistinguishable from age-matched controls $(\mathrm{p}=0.18)$. All scores improved from below to within the population reference range.

Pre-operatively, parents of girls with CAH reported greater discomfort changing diapers in public compared to age-matched controls ( $\mathrm{p}=0.0002)$. Level of comfort improved after surgery $(\mathrm{p}=0.02)$ and was undistinguishable from age-matched controls $(\mathrm{p}=0.43)$. After surgery, all parents of girls with CAH agreed/strongly agreed they were comfortable changing diapers. These findings indicate PACE-F is a sensitive instrument, responsive to change. 
After surgery, mean PACE-F scores increased by 47.2 (SD 16.8). This signifies a large effect size $(47.2 / 16.8=2.8)$.

Cross-sectional analysis: Girls <4 years old with either a pre-or post-FGRS PACE-F score Eleven girls younger than 4 years old were included in this analysis ( 4 pre-, 7 post-FGRS, 13 parental scores). The 7 parents provided PACE-F scores at a median of 19 months after FGRS (85.7\% vaginoplasty, $71.4 \%$ PUM, $85.7 \%$ clitoroplasty). Median pre-FGRS scores were lower than post-FGRS scores (36.1 vs. 77.8, $\mathrm{p}=0.046)$. Three of four pre-FGRS scores were below the population reference range and lower than the age-matched controls (median: 100.0, $\mathrm{p}=0.001$ ). All post-FGRS scores were in the reference range, but lower than controls $(\mathrm{p}=0.01)$.

\section{Cross-sectional analysis: Girls 4-12 years old with CAH after FGRS}

Twenty PACE-F scores were available for 20 girls who underwent FGRS by the age of 3 (90.0\% vaginoplasty, 95.0\% PUM, 95.0\% clitoroplasty) with a median follow-up of 7.8 years (median age 8.5 years). Median scores were undistinguishable between girls with CAH and controls (100.0 vs. 88.9, respectively, $\mathrm{p}=0.77)$. Two of 20 girls $(10.0 \%)$ had PACE-F scores below the population reference range (22.2 and 33.3). This was not statistically distinct from the expected $1 / 20(5 \%)$ of responses being below the $95 \%$ confidence interval-derived population reference range $(p=0.99)$. Both patients underwent a vaginoplasty and PUM without surgical complications in the first year of life. One patient did not undergo a clitoroplasty at initial surgery and parents had concerns about clitoromegaly at age 6 (awaiting patient to make decision about further surgery). Second patient underwent FGRS and was 5 years old at follow-up. 


\section{Discussion}

We present a validation of parent-reported genital appearance scale for use in pre-pubertal girls with CAH. The genital appearance of infants and toddlers with $\mathrm{CAH}$, per parents, is outside the population reference range. Short-term prospective evidence indicates that genital appearance improves after FGRS. Cross-sectional data suggests these results are maintained until puberty.

Few PROs explicitly address issues of appearance and function associated with ambiguous genitalia in a way that is both sensitive and meaningful to patients, families and clinicians. The validation of the parent-reported PACE-F is a necessary first step towards giving those living with $\mathrm{CAH}$ and their families a voice in an effort replace anecdote-based reporting with robust data.

While following the statistical rigor of PRO validation, we wished to ensure that the resulting instrument was clinically meaningful. For that reason, we determined the population reference range ("What is a reference to compare to?") as well as the minimally important difference between scores ("What is a significant difference?"). These characteristics are rarely established for PROs, restricting their real-life implementation. It should be noted that scores derived using PACE-F, or other questionnaires, are intended to be only one of the tools to provide quality care. A single item question was not used as a final PRO. First, a single item tends to have a limited scale, curbing its discrimination ability, sensitivity to change and usefulness in both clinical and research settings. More importantly, a single item ignores potential multiple dimensions of a 
single concept. In this instance, parents of girls with CAH (and women who endorsed the original FGSIS items) submit that genital appearance encompasses aspects of not only satisfaction and embarrassment in general, but also comfort during future sexual contact in particular. We believe a multi-item questionnaire better reflects this multi-faceted concept of female genital appearance.

The mean PACE-F score for girls with CAH, including those without surgery, was 67.3 (SD 28.1), similar to FGSIS scores (linearly transformed to 0-100) for the general population of adult women without known ambiguity (mean: 67.0, SD 21.7). The PACE-F MID was 14, also similar to the FGSIS of 11 points. While the MID for FGSIS is not published, it was derived using the approach outlined in the Methods section (10.8 for 0.5 SD, 8.1 for SEM using Cronbach's alpha). Undoubtedly, the two measures differ in who reports them and how many items they contain, but the similarity of scores informs us about women's perceptions of their own genitalia. It appears that healthy women experience (dis)satisfaction with their genital appearance comparable to parents of girls with $\mathrm{CAH}$, begging the question of what women in the general population consider "normal" or "satisfactory."

Our study has several limitations. Given its small size, further work is required to externally validate PACE-F in larger, particularly prospective, cohorts. We did not assess test-retest reliability of PACE-F scores, although FGSIS has excellent test-retest reliability. ${ }^{12}$ This will be the focus of future work. Despite noting a trend, we did not note a statistically significant correlation between the level of virilization and PACE-F scores. This was most likely due to low statistical power. Alternatively, it is plausible that parental perceptions of genital appearance 
may be more of a more binary phenomenon, rather than a gradient associated with levels of virilization.

Correlations between parental and patient assessments of genital appearance remain unknown. How PACE-F scores relate to anatomical variables, including clitoral appearance, and functional outcomes requires a multi-institutional study. Finally, since all older girls in our study underwent FGRS, it is crucial to note that no scientific data exist on how parents, girls and women with CAH who have not undergone FGRS perceive their genitalia.

\section{Conclusion}

We present a new, validated instrument for a parental assessment of genital appearance in girls with $\mathrm{CAH}$. We also demonstrate improvement in parent-reported appearance after FGRS, which appears to be similar to age-matched controls. PACE-F may prove useful in clinical practice and research.

\section{Figure Legends:}

Figure 1. PACE-F scores stratified by comfort with changing diapers in a public bathroom for parents of girls with $\mathrm{CAH}$ younger than 4 years old $(p=0.03$ test for trend, $n=27)$. 
Figure 2. Parental Assessment of Children's External genitalia scale for Females

(PACE-F) for 10 girls with $\mathrm{CAH}$ prospectively administered before and after female

genital restoration surgery.

\section{References}

1. Hughes IA: Management of congenital adrenal hyperplasia. Arch Dis Child 1988; 63: 1399-1404.

2. Yau M, Khattab A, Pina C et al.: Defects of Adrenal Steroidogenesis, in DeGroot LJ and Jameson JL: Endocrinology: adult and pediatric. Philadelphia, Saunders/Elsevier, 2010, pp 1810-1832.e1816.

3. Rink RC and Kaefer M: Surgical Management of Disorders of Sexual Differentiation, Cloacal Malformation, and Other Abnormalities of the Genitalia in Girls, in Wein AJ, Kavoussi LR and Campbell MF: Campbell-Walsh urology / editor-in-chief, Alan J. Wein ; [editors, Louis R. Kavoussi ... et al.]. Philadelphia, PA, Elsevier Saunders, 2012, vol. 4, pp 3629-3666.

4. Diamond M and Garland J: Evidence regarding cosmetic and medically unnecessary surgery on infants. J Pediatr Urol 2014; 10: 2-6.

5. Lee PA and Houk CP: Commentary to 'Evidence regarding cosmetic and medically unnecessary surgery on infants'. J Pediatr Urol 2014; 10: 7.

6. Krege S, Walz KH, Hauffa BP et al.: Long-term follow-up of female patients with congenital adrenal hyperplasia from 21-hydroxylase deficiency, with special emphasis on the results of vaginoplasty. BJU/nt 2000; 86: 253-258; discussion 258-259.

7. Creighton $\mathrm{S}$, Chernausek SD, Romao R et al.: Timing and nature of reconstructive surgery for disorders of sex development - introduction. J Pediatr Urol 2012; 8: 602-610.

8. Braga LH and Pippi Salle JL: Congenital adrenal hyperplasia: a critical appraisal of the evolution of feminizing genitoplasty and the controversies surrounding gender reassignment. Eur J Pediatr Surg 2009; 19: 203-210.

9. Speiser PW, Azziz R, Baskin LS et al.: Congenital adrenal hyperplasia due to steroid 21hydroxylase deficiency: an Endocrine Society clinical practice guideline. J Clin Endocrinol Metab 2010; 95: 4133-4160.

10. Pasch L, He SY, Huddleston H et al.: Clinician vs Self-ratings of Hirsutism in Patients With Polycystic Ovarian Syndrome: Associations With Quality of Life and Depression. JAMA Dermatol 2016.

11. Hinami K, Alkhalil A, Chouksey S et al.: Clinical significance of physical symptom severity in standardized assessments of patient reported outcomes. Qual Life Res 2016.

12. Herbenick D, Schick V, Reece M et al.: The Female Genital Self-Image Scale (FGSIS): results from a nationally representative probability sample of women in the United States. J Sex Med 2011; 8: 158-166. 
13. Kincaid JP, Fishburne LRP, Jr., Rogers RL et al.: Derivation of new readability formulas (Automated Readability Index, Fog Count and Flesch Reading Ease Formula) for Navy enlisted personnel. Research Branch Report 8-75 1975: 1-48.

14. Joliffe IT and Morgan BJ: Principal component analysis and exploratory factor analysis. Stat Methods Med Res 1992; 1: 69-95.

15. Streiner DL: Figuring out factors: the use and misuse of factor analysis. Can J Psychiatry 1994; 39: 135-140.

16. Bryant FB and Yarnold PR: Principal components analysis and exploratory and confirmatory factor analysis, in Grimm LG and Yarnold RR: Reading and understanding multivariale statistics. Washington, DC, American Psychological Association, 1995, pp 99-136.

17. Gorsuch RL: Factor analysis. Hillsdale, N.J., L. Erlbaum Associates, 1983, pp xvii, 425 p.

18. Streiner DL and Norman GR: Health measurement scales : a practical guide to their development and use. Oxford ; New York, Oxford University Press, 2003, pp xii, 283 p.

19. World Health Organization.: WHO laboratory manual for the examination and processing of human semen. Geneva, World Health Organization, 2010, pp xiv, $271 \mathrm{p}$.

20. Norman GR, Sloan JA and Wyrwich KW: The trulyremarkable universality of half a standard deviation: confirmation through another look. Expert Rev Pharmacoecon Outcomes Res 2004; 4: 581-585.

21. Chassany O, Sagnier P, Marquis P et al.: Patient-Reported Outcomes: The Example of Health-Related Quality of Life - A European Guidance Document for the Improved Integration of Health-Related Quality of Life Assessment in the Drug Regulatory Process. Therapeutic Innovation and Regulatory Science 2002; 36: 209-238.

22. Wyrwich $\mathrm{KW}$, Bullinger M, Aaronson N et al.: Estimating clinically significant differences in quality of life outcomes. Qual Life Res 2005; 14: 285-295.

23. Cohen J: A power primer. Psychol Bull 1992; 112: 155-159.

24. Hays RD, Farivar SS and Liu H: Approaches and recommendations for estimating minimally important differences for health-related quality of life measures. COPD 2005; 2: 63-67.

25. Harris PA, Taylor R, Thielke R et al.: Research electronic data capture (REDCap)--a metadata-driven methodology and workflow process for providing translational research informatics support. J Biomed Inform 2009; 42: 377-381.

26. Rink RC, Metcalfe PD, Kaefer MA et al.: Partial urogenital mobilization: a limited proximal dissection. J Pediatr Urol 2006; 2: 351-356. 


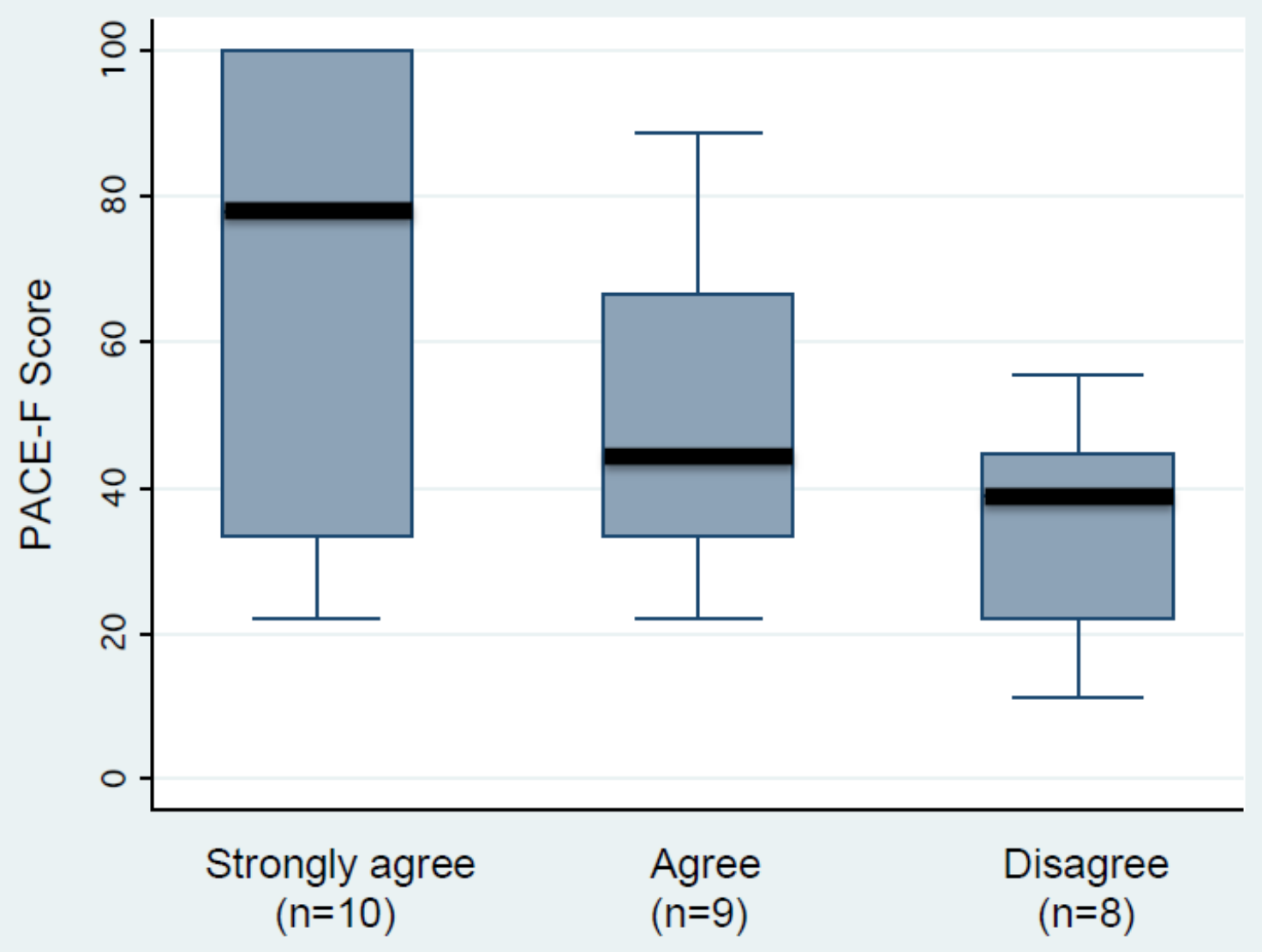

"I am comfortable changing my child's diapers in a public bathroom or change room." 

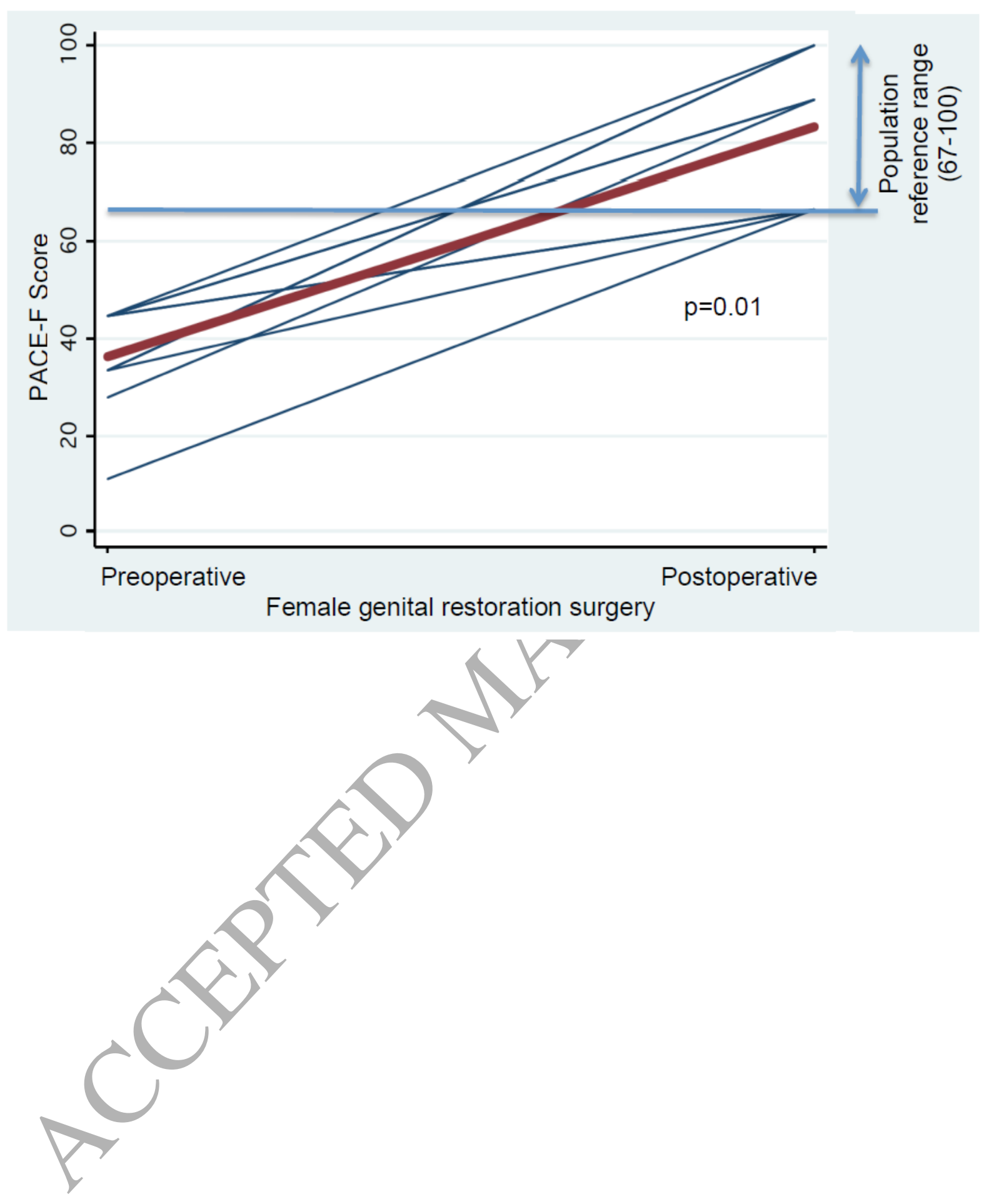


\begin{tabular}{|c|c|c|c|c|}
\hline Question & $\begin{array}{l}\text { Strongly } \\
\text { disagree }\end{array}$ & Disagree & Agree & $\begin{array}{c}\text { Strongly } \\
\text { agree }\end{array}$ \\
\hline $\begin{array}{l}\text { 1. I am satisfied with the way my } \\
\text { child's genitals look. }\end{array}$ & & & & \\
\hline $\begin{array}{l}\text { 2. I would feel comfortable } \\
\text { letting my child's future sexual } \\
\text { partner look at her genitals whe } \\
\text { she is older. }\end{array}$ & & & & \\
\hline $\begin{array}{l}\text { 3. I am not embarrassed about } \\
\text { my child's genitals. }\end{array}$ & & & & \\
\hline
\end{tabular}

Table 1. Parental Assessment of Children's External genitalia scale for Females (PACE-F). Answers options are: strongly disagree (0.0), disagree (11.1), agree (22.2), strongly agree (33.3). Final score range is: 0-100. 


\begin{tabular}{|c|c|c|c|c|c|c|}
\hline $\begin{array}{l}\text { Parents of } \\
\text { girls with } \\
\text { CAH }\end{array}$ & $\mathbf{N}$ & $\begin{array}{c}\text { Median age } \\
\text { (years, range) }\end{array}$ & $\begin{array}{l}\text { Mean } \\
\text { (SD) }\end{array}$ & $\begin{array}{l}\text { Median } \\
\text { (range) }\end{array}$ & $\begin{array}{c}\% \\
\text { Scoring } \\
\text { Minimum }\end{array}$ & $\begin{array}{c}\% \\
\text { Scoring } \\
\text { Maximum }\end{array}$ \\
\hline Overall & 56 & $\begin{array}{c}3.5 \text { (6 months- } \\
12.0 \text { years) }\end{array}$ & $\begin{array}{c}67.3 \\
(28.1)\end{array}$ & $\begin{array}{c}66.7(11.1- \\
100.0)\end{array}$ & 0.0 & \\
\hline $\begin{array}{l}\text { Without } \\
\text { FGRS }\end{array}$ & 19 & $\begin{array}{l}7 \text { months (6 } \\
\text { months-3.1 } \\
\text { years) }\end{array}$ & $\begin{array}{c}37.4 \\
(114.9)\end{array}$ & $\begin{array}{r}33.3(11 \\
77.8)\end{array}$ & & 0.0 \\
\hline $\begin{array}{l}\text { After FGRS } \\
\text { (Less than } 4 \\
\text { years) }\end{array}$ & 17 & $\begin{array}{c}14 \text { months (11 } \\
\text { months-3.9 } \\
\text { years) }\end{array}$ & $\begin{array}{c}81.1 \\
(13.5)\end{array}$ & & 0.0 & 23.5 \\
\hline $\begin{array}{l}\text { After FGRS } \\
\text { (4-12 years) }\end{array}$ & 20 & $8.5(4.3-12.0)$ & 83.9 & $\begin{array}{c}100(22.2- \\
100.0)\end{array}$ & 0.0 & 60.0 \\
\hline $\begin{array}{c}\text { Parents of } \\
\text { girls } \\
\text { without } \\
\text { CAH }\end{array}$ & & & $\begin{array}{l}\text { Mean } \\
\text { (SD) }\end{array}$ & $\begin{array}{l}\text { Median } \\
\text { (Range) }\end{array}$ & $\begin{array}{c}\% \\
\text { Scoring } \\
\text { Minimum }\end{array}$ & $\begin{array}{c}\% \\
\text { Scoring } \\
\text { Maximum }\end{array}$ \\
\hline Overall $^{\mathrm{a}}$ & 139 & $\begin{array}{c}3.5 \text { (2 months- } \\
12.0)\end{array}$ & $\begin{array}{c}89.1 \\
(13.8)\end{array}$ & $\begin{array}{c}100.0(55.6- \\
100.0)\end{array}$ & 0.0 & 53.2 \\
\hline $\begin{array}{c}\text { Less than } 4 \\
\text { years }\end{array}$ & 68 & $\begin{array}{c}1.3 \text { (2 months- } \\
3.9)\end{array}$ & $\begin{array}{c}91.2 \\
(12.8)\end{array}$ & $\begin{array}{c}100(55.6- \\
100.0)\end{array}$ & 0.0 & 58.8 \\
\hline 4-12 years & 71 & $6.1(4.0-12.0)$ & 86.8 & 88.9 (66.7- & 0.0 & 48.4 \\
\hline
\end{tabular}




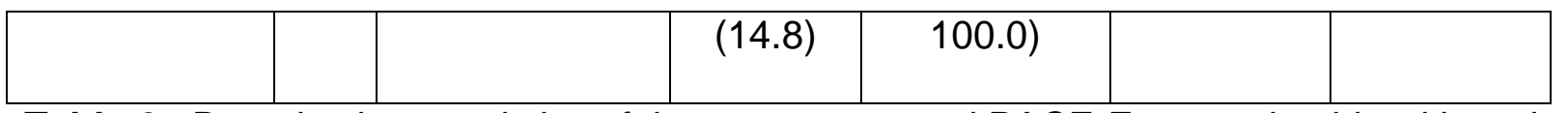

Table 2. Domain characteristics of the parent-reported PACE-F scores in girls with and without $\mathrm{CAH}$.

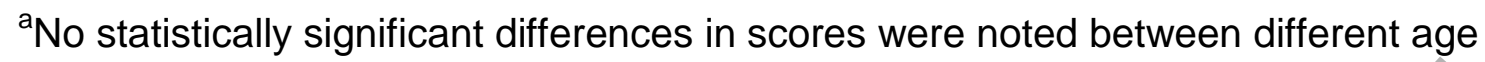
groups. 